\title{
R.L. DALRYMPLE
}

Abstract

Several methods of grass seed harvest exist. One method that performs well for farm and ranch circumstances is a homemade pickup grass seed stripper. This stripper affords a means of economical seed harvest for many grass seeds.

Grass seeds from some tall grasses can be readily harvested with specialized commercial grass seed strippers. Numerous properly operated combines in good condition can also be used to harvest grass seeds under certain conditions. Many approaches to grass seed harvest are possible, but economic considerations and unavailability of specialized machines or combines in many areas often prevent their use.

Tall grass seeds can be harvested with a homemade pickup grass seed stripper (Fig. 1). We have used this machine extensively to

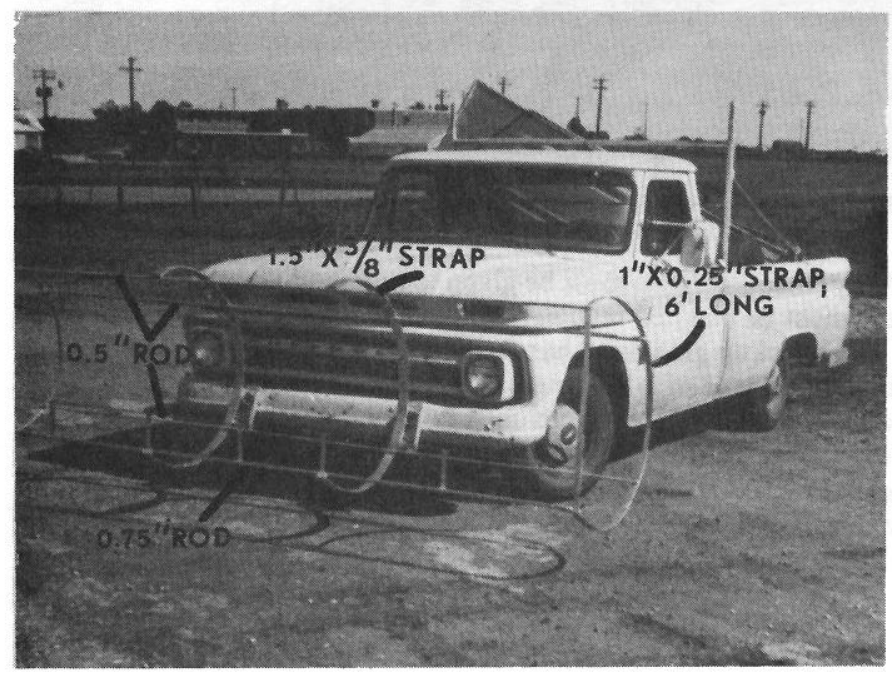

Fig. 1. A pickup grass seed stripper frame ready to cover.

harvest "Old World" bluestem seed. Early models of this particular type stripper were developed about $1961 .^{1}$ It was originally conceived to harvest bluestem seed in southern Oklahoma. Since the stripper's original evolution, it has undergone many alterations and changes in method of construction but the basic design and operation have remained much the same. One of the better pick grass seed strippers is shown in Figure 3. This unit allows better airflow through the unit, thus allowing better seed deposition in the hopper and it has a deeper, higher capacity hopper than cloth covered units. Figures 1 to 5 show the basic construction of the pickup grass seed stripper. Numerous methods and materials have been and can be used. Every farm and ranch engineer has his own ideas; however, some characteristics of the stripper must be maintained.

1. It must be somewhat flexible, but the frame must be constructed of strong enough steel to prevent it from easily bending out of shape.

2. It should be hinged at the bumper attachment for height and adjustment and flexibility.

3. It should be at least as wide as the truck operating it and a 10 to 12 -foot wide model is excellent in most cases.

\footnotetext{
Author is a pasture and crop specialist with the Agricultural Division, Nobel Foundation, 2510 Highway 70 East, Ardmore, Okla. 73401 Manuscript received May 31, 1983.

'Original development of these machines is credited to Archie Welch, District Conservationist, and Fred Koons, District Manager, while they were employed by the Arbuckle Conservation District of the Soil Conservation Service at Ardmore, Okla.
}



Fig. 2. A pickup grass seed stripper completed and ready to use. This unit has been used many times since its construction in 1966.

4. It must contain at least two flailing bars. If the grass seedheads are greatly variable in height, more flailing bars are needed.

Grass seed is considered ready to strip when about $25 \%$ or more of it will readily strip off the heads when the heads are pulled through a firmly closed hand. Seed is then harvested with the pickup grass seed stripper by driving through the seed harvest area at appropriate speeds with the flailing bars down into the seedhead area. Speed is the force that flails the easily stripped seed into the stripper hopper. Actual speeds needed are variable from 10 to 20

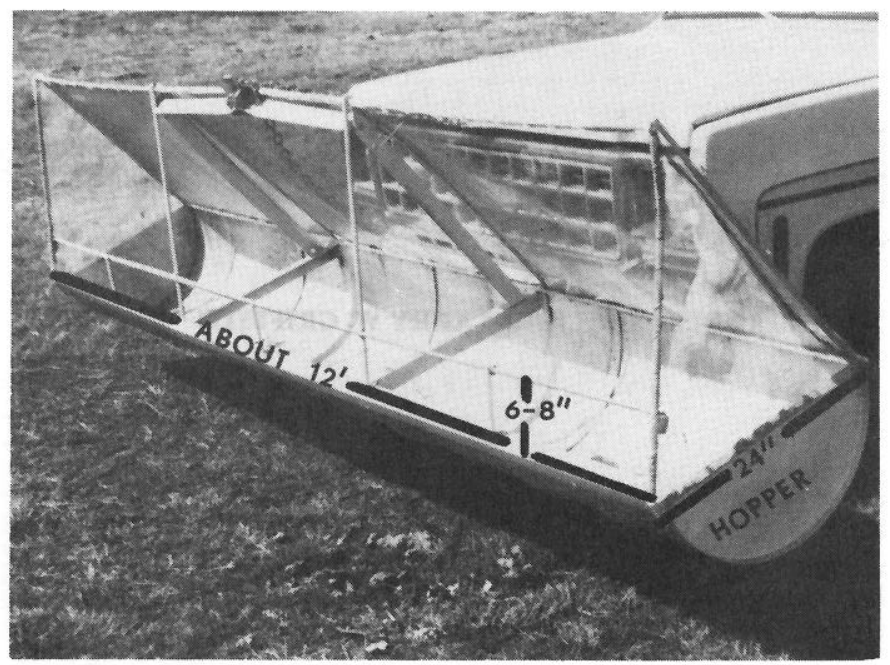

Fig. 3. An improved version of a pickup grass seed stripper with fine screen cover and half-barrel hopper bottom.

miles per hour depending on seed harvest conditions. A trial and error approach must be used to determine best speed for gathering easily stripped seed and leaving greener immature seed and forming seedheads for later stripping.

A field properly stripped the first time can be restripped numerous times as seed continues to form and ripen. We have harvested fields of "Old World" bluestem up to 3 times and I believe even 
more strippings are possible under most proper harvest conditions and close stripper operation. Repeated strippings should be made using the same travel tracks. It is easy to strip 5 or more acres per hour even when considering the seed bagging and radiator servicing time. A 10 -foot wide unit operated at $15 \mathrm{mph}$ will harvest 18 acres per hour of travel time. Servicing time reduces the actual harvested acreage per hour.

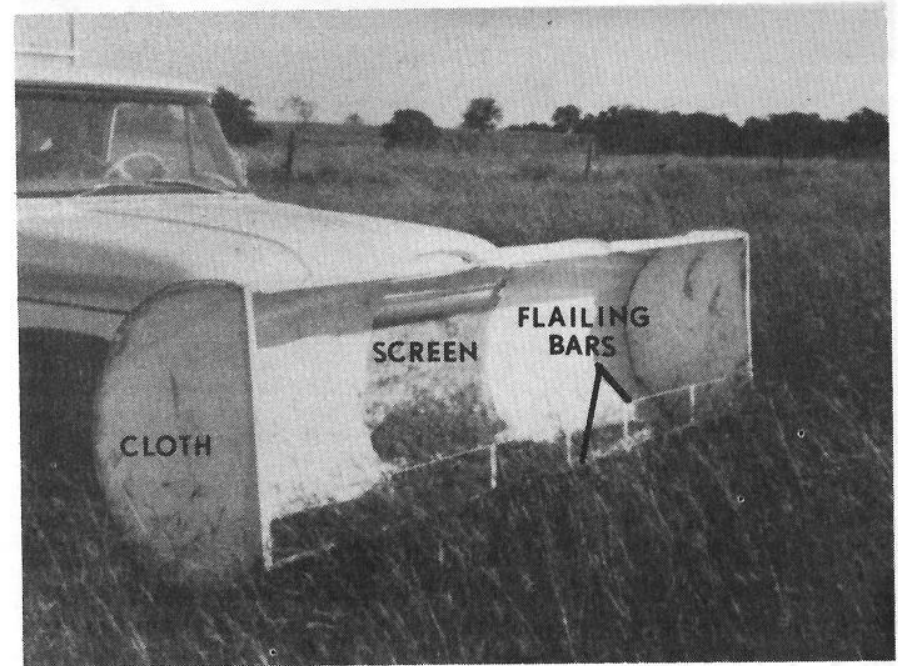

Fig. 4. A Noble Foundation model of a cloth-covered pickup grass seed stripper harvested a light yielding crop of an "Old World" bluestem.

The hopper must be emptied by hand when it reaches about two-thirds full. An excellent approach is to bag the seed in large burlap or other porous bags. The seed will be too wet for storage without drying. It must be spread in a six- to 12 -inch layer in an area protected from moisture and stirred daily or twice daily until it is dry. A fan, or other airflow blowing over the seed, is a great aid in drying the seed.

Major problems with this method are hidden obstacles in the field such as, bull holes, stumps, etc., and pickup radiator clogging.

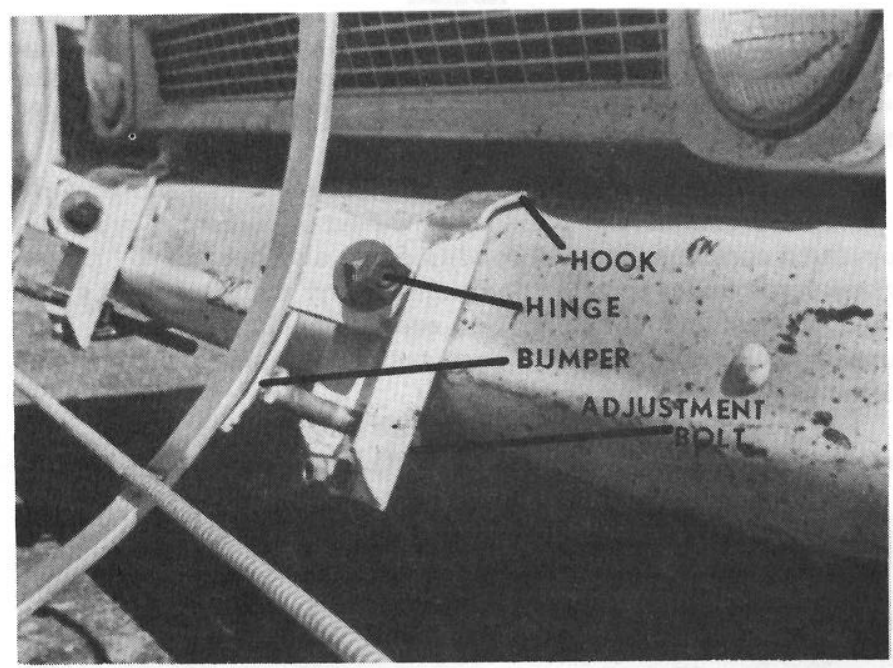

Fig. 5. One method of attaching a pickup grass seed stripper to a pickup bumper.

Very close attention must be given to radiator clogging. The radiator must be cleaned regularly to prevent engine overheating.

The pickup grass seed harvester is obviously intended to be used to harvest seed of tall type grasses. The unit performs well on areas where some grazing has reduced foliage volume or other situtions where foliage is not a problem. As with other harvest methods, the pickup grass seed stripper is difficult or impossible to use well in extremely thick, extremely tall, or lodged tall grasses. 